\title{
Influence of Some Preparative Parameters on Microstructure and Electrochromic Behavior of Sprayed Iridium Oxide Films
}

\author{
S. A. Mahmoud, A. S. Riad, M. M. El-Deeb, and Tarek Ben Nasrallah
}

\begin{abstract}
Electrochromic iridium oxide thin films were deposited by spray pyrolysis technique onto indium-doped tin oxide (ITO) coated glass substrates using iridium chloride as an aqueous solution. The influence of the substrate temperature, the deposition period of time and the solution molarity have been investigated as related to the film's electrochromic (EC) performance. The electrochromic properties of the films were investigated in a $\left(0.5 \mathrm{M} \mathrm{H}_{2} \mathrm{SO}_{4}\right)$ aqueous electrolytic solution using cyclic voltammetry (CV). The transmittance has been measured over the spectral wavelength range between 300 and $2400 \mathrm{~nm}$. The substrate temperature $\left(T_{\text {sub }}\right)$, the deposition period of time, the solution molarity and the colouration and bleaching potentials were optimized and found to be $400{ }^{\circ} \mathrm{C}, 10$ $\min , 0.02 \mathrm{M}, \pm 0.8 \mathrm{~V}$, respectively. The films have acquired a maximum transmittance solar modulation $\Delta \mathrm{T}_{\mathrm{s}}$ and a maximum visible modulation $\Delta T v$ at $630 \mathrm{~nm}$ optimal optical modulation. The iridium oxide thin films have demonstrated a pronounced anodic electrochromic behavior owing to $\mathrm{Ir}^{+4} \rightleftharpoons \mathrm{Ir}^{+3}$ intervalance charge transitions.
\end{abstract}

Index Terms-Electrochromic iridium oxide, cyclic voltammetry, solar and visible modulation, coloration and bleaching.

\section{INTRODUCTION}

Electrochromism is the process by which a material exhibits reversible and persistent colour change with applied electric current or applied field [1], [2]. Electrochromic materials switch from the uncoloured state to the coloured state by simultaneous ion and electron injection and consequently have potential application in energy efficient "Smart Windows" [3], mirrors with variable reflectance and high contrast non emissive information displays [1], [2]. Two categories of electrochromism are defined based on the absorption wavelengths namely; visible electrochromism in the wavelength range of 350 to $850 \mathrm{~nm}$ and non-visible electrochromism in the wavelength range $<350 \mathrm{~nm}$ and $>$ $850 \mathrm{~nm}$. Iridium oxides are known as anodic electrochromic material in which they are able to change their colour from transparent to a deep brown look under positive applied

Manuscript received October 31, 2013; revised December 20, 2013.

S. A. Mahmoud and A. S. Riad are with the Physics Department, Faculty of Science, Hail University, Hail, Kingdome of Saudi Arabia (e-mail: samahmoud2002@yahoo.com,asr_rizk@hotmail.com).

M. M. El-Deeb is with Chemistry Department, Faculty of Science, Hail University, Hail, Kingdome of Saudi Arabia and Chemistry Department, Faculty of Science, Beni-Suef University, 62514 Beni-Suef, Egypt.

Tarek Ben Nasrallah is with the Physics Department, Faculty of Science, Hail University, Hail, Kingdome of Saudi Arabia and Université de Tunis El Manar, Faculté des Sciences de Tunis, Unité de physique des dispositifs à semi-conducteurs, Tunis, Tunisie (e-mail: nasrallah.tarek@gmail.com). potentials and reversibly bleached under a negative applied potential [4]. Iridium oxides are well known and interested material due to their wide range of applications in optical data storage media [5], fuel cell [6], biosensor [7], corrosion protection of metals [8], electrocatalysis [9] and in micro-electronic devices and $\mathrm{pH}$ sensors [10]. Iridium oxide/hydroxide films have distinguishable characteristics that include a fast colouring and bleaching time periods $(<50$ ms), large open circuit memory ( $>90 \%$ ), high stability ( $\sim 107$ cycles) and relatively sharp threshold voltage [11]. Iridium oxide thin films have been prepared using variety of techniques such as thermal oxidation [12], anodic oxidation [13], reactive sputtering [14], electrodeposition [15], sol-gel processing [16] and spray pyrolysis [17].

The iridium oxide films prepared in this work have been deposited onto ITO-coated glass substrates using spray pyrolytic iridium chloride solution as well as the effect of substrate temperature, solution molarity and the deposition time have been investigated and discussed in accordance with the films' electrochromic activation.

\section{EXPERIMENTAL}

\section{A. Preparation of Electrochromic Iridium Oxide}

Indium tin oxide (ITO)-coated glass substrates were first cleaned very carefully by ultrasonic degreasing process with isopropanol and deionized water. A set of iridium oxide thin films were then deposited on the ITO-coated glass substrates using the aqueous solution of iridium chloride $\left(\mathrm{IrCl}_{3} \cdot 3 \mathrm{H}_{2} \mathrm{O}\right)$ under different substrate temperatures, different solution molarity ratios and for various time. The samples were then annealed at $600{ }^{\circ} \mathrm{C}$ for 2 hours.

The optical transmittance of the films was measured in the wavelength range between $300 \mathrm{~nm}$ to $2500 \mathrm{~nm}$ using SHIMADZU UV 3101 PC: UV-VIS-NIR double beam spectrophotometer. The electrochromic (EC) characteristics of the iridium oxide thin films deposited onto ITO-coated glass substrates were then investigated at different substrate temperatures (ranging from 350 to $500{ }^{\circ} \mathrm{C}$, in steps of $50{ }^{\circ} \mathrm{C}$ ) and with solution molarity ratios (between 0.005 and $0.03 \mathrm{M}$ ). The iridium oxide thin films deposited onto ITO-coated glass substrates were used as working electrodes in a three-electrode electrochemical cell containing $0.5 \mathrm{M} \mathrm{H}_{2} \mathrm{SO}_{4}$ solution. The Platinum sheet and saturated calomel electrode (SCE) are used as a counter and reference electrodes respectively.

A JEOL X-ray diffractometer (model JSDX-60PA) with $\mathrm{Ni}$-filtered and $\mathrm{Cu}$ : $\mathrm{K} \alpha$ radiation $\left(\lambda K_{\alpha}=0.154184 \mathrm{~nm}\right.$ ) was 
used to obtain diffraction patterns in order to investigate the microstructure of the films. Continuous data acquisition scan with slow scanning speed $(1 \% \mathrm{~min})$ and short time constant (1sec) was performed for the samples. The scan has covered the Bragg's angle range $(2 \theta)$ between $10^{\circ}$ to $60^{\circ}$. It was meant to cover all the possible diffraction peaks expected for such material.

A mechanical stylus method (MSM - Sloan Dektak, model 11A) was used to measure the film thickness for the annealed samples [18].

\section{RESUlTS AND DisCUSSION}

\section{A. Formation of Iridium Oxide Thin Films}

The aqueous iridium chloride solution is sprayed onto preheated ITO- coated glass substrates. The pyrolytic decomposition process used to form the iridium oxide thin solid films is based on the following chemical reaction:

$$
\begin{aligned}
& 2 \mathrm{Ir} \mathrm{Cl}_{3} \cdot 3 \mathrm{H}_{2} \mathrm{O} \rightarrow \mathrm{Ir}_{2} \mathrm{O}_{3}+6 \mathrm{HCl} \uparrow \\
& \mathrm{Ir}_{2} \mathrm{O}_{3} \stackrel{600^{\circ} \mathrm{C}, 2 \mathrm{~h}}{\longrightarrow} 2 \mathrm{IrO}_{2}
\end{aligned}
$$

The deposited films were found to be uniform, strongly adherent to the substrates and blackish colour. Fig. 1 shows the XRD patterns for the iridium oxide films deposited on ITO-coated glass substrates at various substrate temperatures at constant solution molarity $(0.005 \mathrm{M})$ and fixed deposition time (10 min.). The films were then annealed at $600 \mathrm{oC}$ for two hours, the thickness of the annealed films was found to vary between 160 and $325 \mathrm{~nm}$ as the substrate temperature increases from 350 to $500{ }^{\circ} \mathrm{C}$, respectively. From the figure, no peaks are found to appear in the XRD patterns when the substrate temperature is fixed at $\mathrm{T}_{\text {sub }}=350{ }^{\circ} \mathrm{C}$, indicating that the films are of amorphous nature. As the substrate temperature increases $\left(T_{\text {sub }} \geq 400{ }^{\circ} \mathrm{C}\right)$, the microstructure of the films transforms into the polycrystalline phase that is characterized by three crystalline orientations defined by Miller indices (110), (101) and (200). The planes representing the Miller indices are referred to $\mathrm{IrO}_{2}$ tetragonal structure with a preferred orientation in the $<101>$ direction (card no. ICDD 15-870). The degree of cyrstallinity, as indicated by the XRD peak intensity, increases as the substrate temperature increases. The Voigt average crystalline size is estimated to be around $14 \mathrm{~nm}$ for all preparative conditions. Kawar et al. [19], reported a comparable value of crystallite size for similar structural phase prepared by spray pyrolysis technique.

Fig. 2 shows the XRD patterns for Ir-oxide thin films as a function to the solution molarity, films prepared at solution molarity of $0.005 \mathrm{M}$ showed no crystalline characteristics indicating that the samples are of amorphous nature. The films became polycrystalline in nature while increasing the solution molarity. It is worth mentioning that the peaks in the X-ray diffraction patterns, defined by the (110), (101), (200) and (211) Miller indices, characterizes the IrO2 polycrystals formed in the rutile structure with tetragonal primitive lattice.

The films demonstrate a preferred crystalline growth along the $<101>$ direction. The improvement in the intensity of the peaks is may be attributed to either grain-growth associated with higher film thickness, or due to an improvement in the degree of crystallinity by increasing the solution molarity or due to both factors.

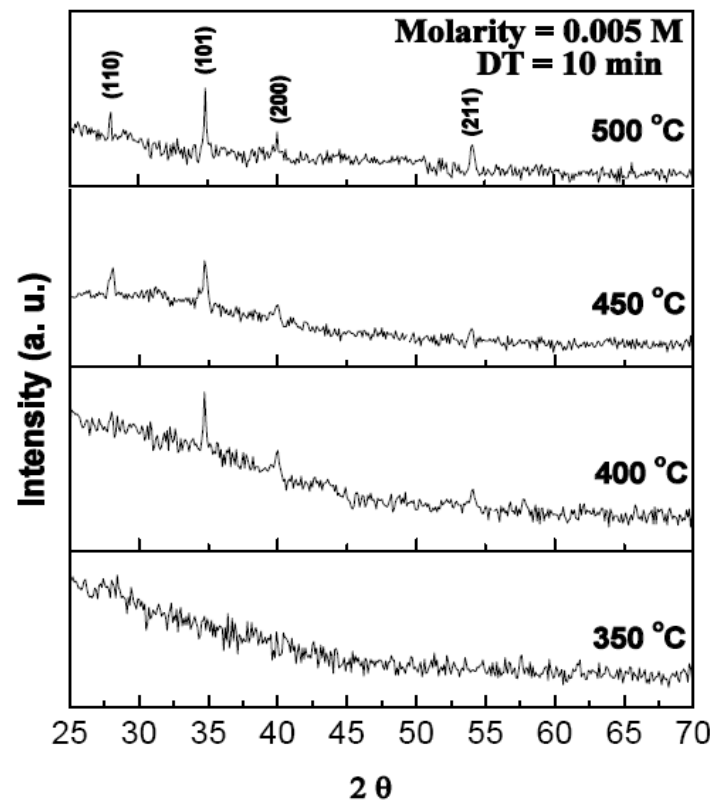

Fig. 1. Effect of substrate temperature on the X-ray diffractgrams of $\mathrm{IrO}_{2}$ films prepared from $0.005 \mathrm{M}$ iridium chloride solution at constant deposition time (10 $\mathrm{min})$.

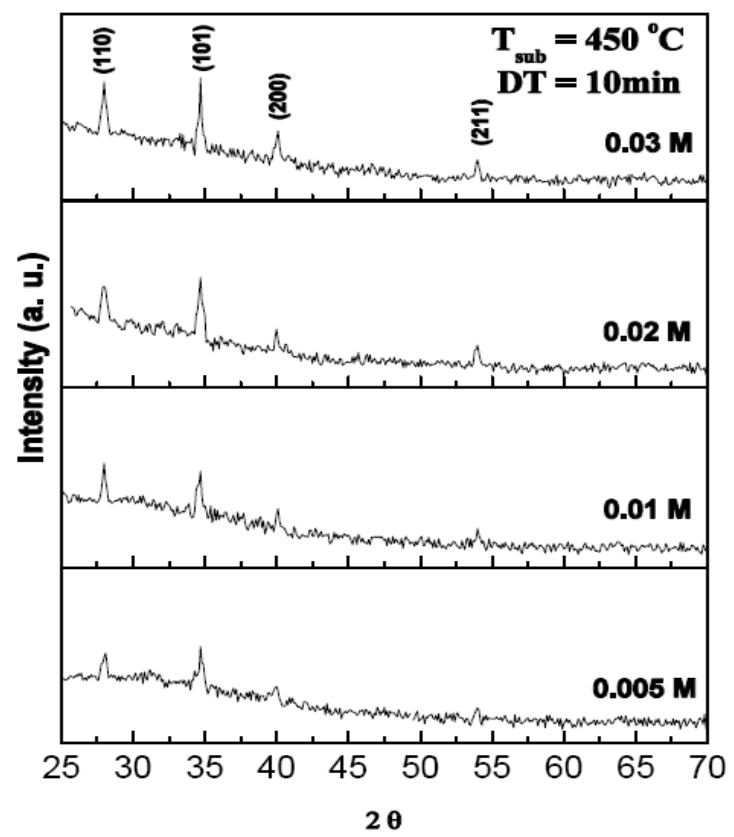

Fig. 2. Effect of solution molarity on the X-ray diffractgrams of $\mathrm{IrO}_{2}$ films deposited at constant deposition time $(10 \mathrm{~min})$ and substrate temperature is $450^{\circ} \mathrm{C}$.

\section{B. Electrochromic Characterization}

When an external voltage $( \pm 0.8 \mathrm{~V})$ is applied between the working and the counter electrodes (with respect to the reference electrode) in the cyclic voltammetry (CV), the film turn bluish -black in coloration process that occurs in few seconds of voltage application. The optical transmittance measurements were then performed for the samples using the background transmission taken from the ITO-coated glass substrate as a reference sample. The samples were then bleached at $-0.8 \mathrm{~V}$. In similar procedure, the transmittance 
was measured under the bleaching conditions. The spectral transmittance of the iridium oxide films deposited at different substrate temperatures in coloured and bleached state are shown in Fig. 3. The overall transmittance decreases after colouration occurs, indicating the formation of color centers due to coloration. As the substrate temperature increases, the electrochromic performance increases and deteriorates for films grown at substrate temperature $\mathrm{T}_{\text {sub }}>350{ }^{\circ} \mathrm{C}$ where crystallites began to grow [16].

The colouration/bleaching process formula proposed for the spray deposited Ir-oxide thin films is either [2], [19]:

$$
\begin{gathered}
\mathrm{Ir}(\mathrm{OH})_{3}+\mathrm{H}+\mathrm{e}^{-} \stackrel{\text { colored } / \text { bleachte }}{\longrightarrow} \mathrm{IrO}_{2} \mathrm{H}_{2} \mathrm{O} \\
a t+0.8 V V_{S}(S C E)
\end{gathered}
$$

or

$$
\begin{gathered}
\mathrm{Ir}(\mathrm{OH})_{3}+\mathrm{OH}+\mathrm{e}^{-} \stackrel{\text { colored /bleachte }}{\longleftrightarrow} \mathrm{IrO}_{2} \cdot 2 \mathrm{H}_{2} \mathrm{O} \\
a t+0.8 V V_{S}(S C E)
\end{gathered}
$$

When an external voltage of $+0.8 \mathrm{~V}$ is applied between the working and the counter electrodes, a transition of $\mathrm{H}^{+}$ions to the iridium sites $\left(\mathrm{Ir}^{+3}\right)$ occur causing films colouration state. However, an application of $-0.8 \mathrm{~V}$ to the samples extracts $\mathrm{H}+$ ions from the iridium sites $\left(\mathrm{Ir}^{+4}\right)$ causing films bleaching [16], [20].

The calculation of photopic contrast ratio was performed for iridium oxide thin films at light wavelength of $630 \mathrm{~nm}$ using the relation:

$$
\text { Constrast ratio }=\left(T_{b} / T_{c}\right)_{360 \mathrm{~nm}}
$$

where $T_{b}$ is the transmittance at bleached state and $T_{c}$ is the transmittance at colored state. The values of photopic contrast ratio are calculated as a function of substrate temperature and listed in Table I. The photopic ratio decreases slightly from 1.188 to 1.05 as the substrate temperatures increase from 350 to $500{ }^{\circ} \mathrm{C}$. Increasing the substrate temperature from $350-500{ }^{\circ} \mathrm{C}$ increases the crystallinity of samples that cause decreases in the contrast ratio due to the decreasing in the photo absorption. This observation is in a good agreement with data reported by Patil et al.[20].

Fig. 4 shows the spectra variation of the optical transmittance for $\mathrm{IrO}_{2}$ thin films as a function of solution molarity. The transmittance of the bleached state varies between 0.75 and 0.52 as the solution molarity changes between 0.005 and $0.03 \mathrm{M}$, respectively.

The reduction in transmittance, over the whole spectrum, may be attributed to the increase in both film thickness and crystallinity of the films. Hence, an increase in the carrier concentration that arises from the defects' ionization and an increase in the carriers mobility causing higher film absorption [20]. The photopic contrast ratio is listed in Table II as related to the solution molarity. It is clear that, the photopic ratio is increased slightly as the solution molarity increases while the contrast ratio reaches its maximum value at $0.02 \mathrm{M}$ solution molarity.
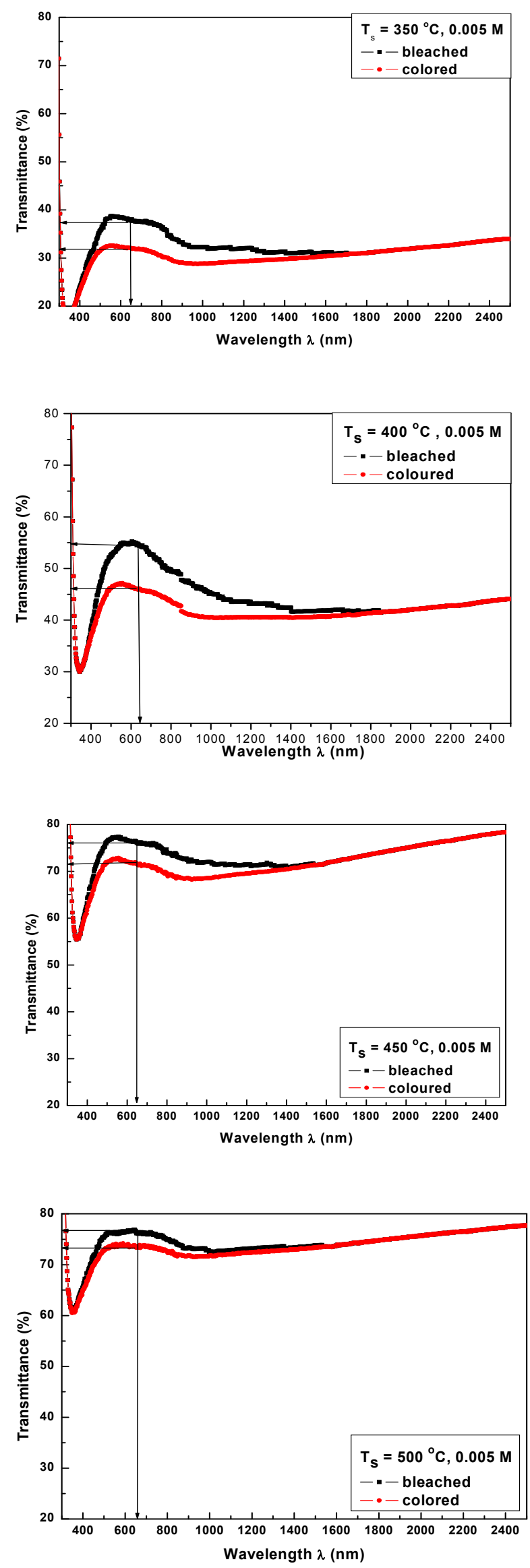

Fig. 3. Transmission of colored and bleached at different substrate temperature, $350,400,450$ and $500{ }^{\circ} \mathrm{C}$ at constant solution molarity $0.005 \mathrm{M}$.

\section{Optical Modulation}


The optical characteristics for the iridium oxide films are found through calculating the solar and visible transmittance in the colored and bleached states, respectively. The optical modulation $\left(\Delta T_{s}\right)$ is also found by using the following relations:

$T_{V}=\frac{\int_{380 \mathrm{~nm}}^{780 \mathrm{~nm}} T(\lambda) d \lambda}{\int_{380 \mathrm{~nm}}^{780 \mathrm{~nm}} V(\lambda) d \lambda} \quad T_{s}=\frac{\int_{300 \mathrm{~nm}}^{2400 \mathrm{~nm}} T(\lambda) G(\lambda) d \lambda}{\int_{300 \mathrm{~nm}}^{2400 \mathrm{~nm}} G(\lambda) d \lambda}(6)$

where $G(\lambda)$ is the solar spectrum at $A M_{2}, V(\lambda)$ is the photopic luminous efficiency function defining the eye sensitivity.
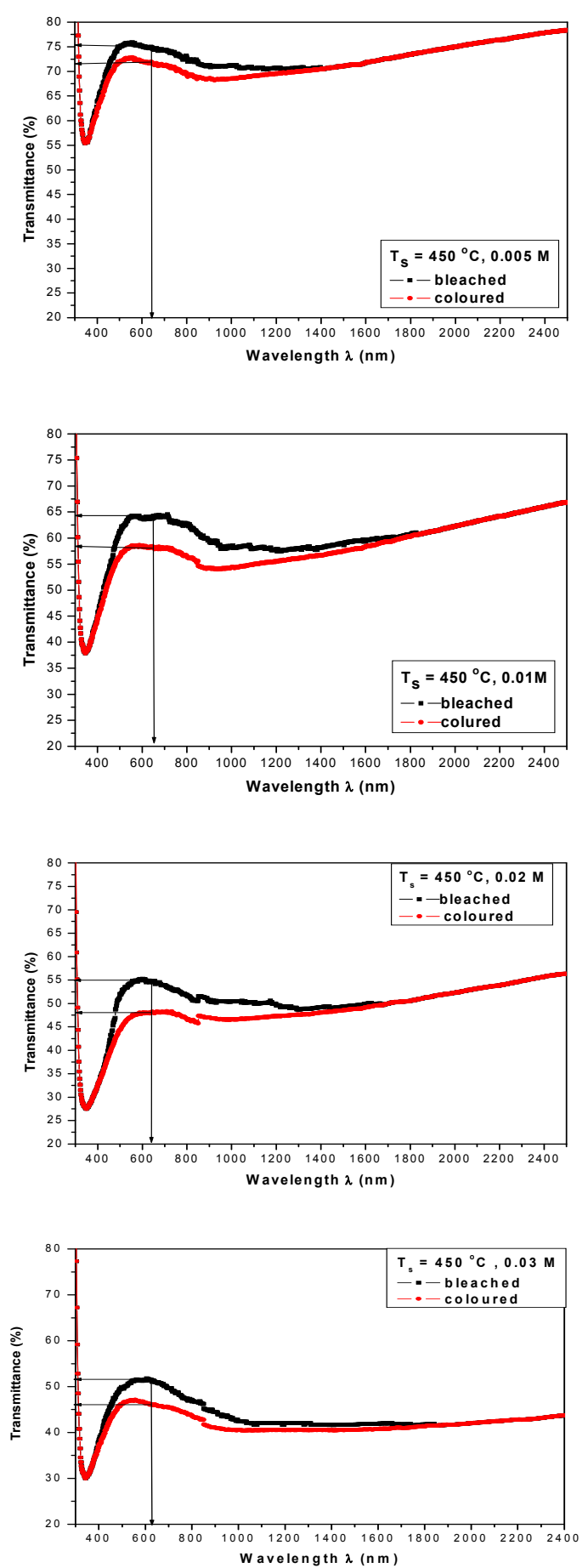

Fig. 4. Transmission of colored and beleached at different solution molarity, $0.005,0.01,0.02$ and $0.03 \mathrm{M}$ at constant substrate temperature $450^{\circ} \mathrm{C}$.

Fig. 5 shows the behavior of the solar transmittance as related to the substrate temperature and the solution molarity. The solar transmittance in the case of the bleached state is greater than that of the coloured state over the whole ranges of the substrate temperature and the solution molarity.

TABLE I: TRANSMITTANCE OF COLORED AND BLEACHED STATES, THE SOLAR TRANSMitTANCE (AT $\Lambda=630 \mathrm{NM}$ ), THE PHOTOPIC CONTRAST RATIO AND THE CHANGE IN OPTICAL DENSITY $(\Delta \mathrm{OD})$ AS RELATED TO THE

\begin{tabular}{|c|c|c|c|c|c|}
\hline \multicolumn{6}{|c|}{ SUBSTRATE TEMPERATURE } \\
\hline$T_{\text {sub. }}\left({ }^{\mathrm{o}} \mathrm{C}\right)$ & $\begin{array}{l}\% T c \\
\text { at } 630 \mathrm{~nm} \\
\text { colored } \\
\text { state }\end{array}$ & $\begin{array}{l}\% T_{b} \\
\text { at } 630 \mathrm{~nm} \\
\text { bleached } \\
\text { state }\end{array}$ & $\left(\Delta T_{S}\right)$ & $\left(T_{b} / T_{c}\right)$ & $\Delta \mathrm{OD}$ \\
\hline 350 & 0.32 & 0.38 & 0.06 & 1.188 & 0.172 \\
\hline 400 & 0.47 & 0.56 & 0.09 & 1.192 & 0.176 \\
\hline 450 & 0.71 & 0.76 & 0.05 & 1.070 & 0.068 \\
\hline 500 & 0.73 & 0.77 & 0.04 & 1.055 & 0.054 \\
\hline $\begin{array}{l}\text { Average } \\
\text { value }\end{array}$ & 0.558 & 0.618 & 0.06 & 1.126 & 0.119 \\
\hline 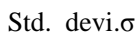 & 0.171 & 0.161 & 1.871 & 0.064 & \\
\hline
\end{tabular}

TABLE II: THE TRANSMITTANCE OF COLORED AND BLEACHED STATES, THE SOLAR TRANSMITTANCE (AT $\Lambda=630 \mathrm{NM})$, THE PHOTOPIC CONTRAST RATIO AND THE CHANGE IN OPTICAL DENSITY $(\triangle \mathrm{OD})$ AS RELATED TO THE

\begin{tabular}{|l|l|l|l|l|l|}
\hline $\begin{array}{l}\text { Solution } \\
\text { molarity } \\
\mathrm{M}\end{array}$ & $\begin{array}{l}\text { \% } \\
630 \mathrm{~nm} \\
\text { colored } \\
\text { state }\end{array}$ & $\begin{array}{l}\text { \% } \\
630 \mathrm{~nm} \\
\text { bleached } \\
\text { state }\end{array}$ & $\Delta T_{S}$ & $\left(T_{b} / T_{c}\right)$ & $\Delta \mathrm{OD}$ \\
\hline 0.005 & 0.72 & 0.75 & 0.03 & 1.042 & 0.041 \\
\hline 0.01 & 0.58 & 0.64 & 0.06 & 1.103 & 0.098 \\
\hline 0.02 & 0.48 & 0.55 & 0.07 & 1.146 & 0.136 \\
\hline 0.03 & 0.47 & 0.52 & 0.05 & 1.106 & 0.101 \\
\hline $\begin{array}{l}\text { Average } \\
\text { value }\end{array}$ & 0.563 & 0.615 & 0.053 & 1.099 & 0.094 \\
\hline Std. devi. $\sigma$ & 0.101 & 0.089 & 1.479 & 0.037 & \\
\hline
\end{tabular}
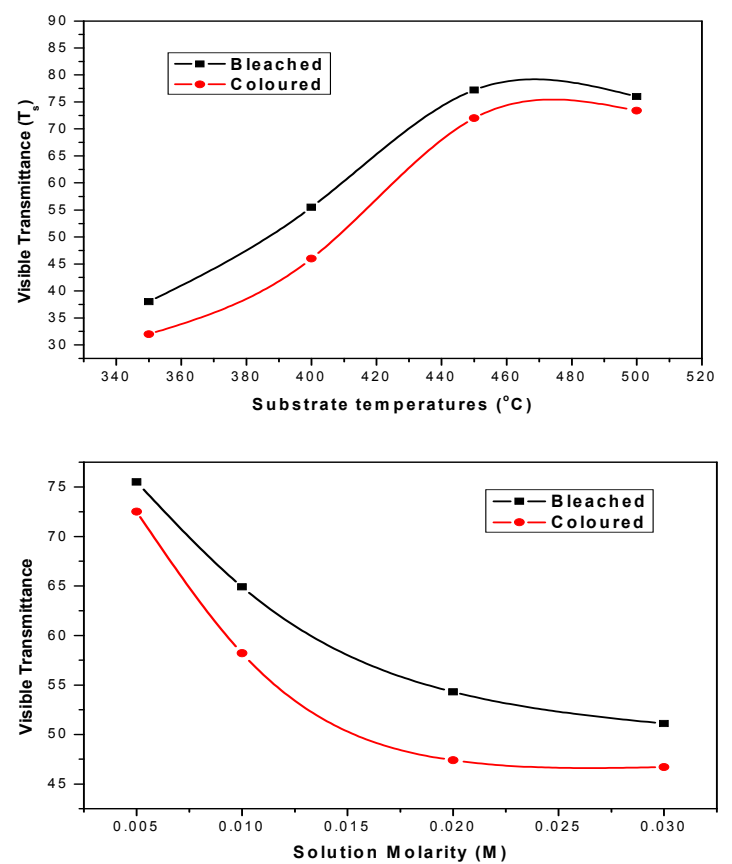

Fig. 5. Solar transmisition with different substrate temperature and solution molarity.

On the other hand, the colouration (absorption) process reaches its maximum influence at around $450{ }^{\circ} \mathrm{C}$ substrate 
temperature and at $0.005 \mathrm{M}$ solution molarity.

The colouration process, therefore, is highly influenced by the film structure rather than the film thickness. This behavior is defined by the apparent decrease in the film coloration (absorption) observed at high substrate temperature $\left(T_{\text {sub }}<450{ }^{\circ} \mathrm{C}\right)$ due to the formation of compact crystalline iridium oxides material. This observation is may be attributed to the fact that ion insertion in iridium oxide takes place through filling the defects based on absorption modulation process. The crystalline size of $\mathrm{IrO}_{2}$ grown at higher substrate temperature $\left(T_{\text {sub }}\right)$ is found to be around 14 $\mathrm{nm}$ which is considered to be too dense for ions intercalation [2], [21]. The Amorphus and polycrystalline iridium oxide films were grown onto ITO substrate in order to investigate the dependence of the electrochromic performance on their preparation conditions.

The iridium oxide thin films deposited in $0.5 \mathrm{~N} \mathrm{H}_{2} \mathrm{SO}_{4}$ aqueous solution under various conditions were investigated for electrochromic effect.

The variation of the solar optical modulation $\left(\Delta T_{s}=T_{s b}\right.$ $T_{s c}$ ) with respect to the substrate temperature and the solution molarity, prepared in the first cycle, are shown in Fig.6. An increase in the substrate temperature produces an increase in the colouration efficiency. The colouration efficiency reaches its maximum value at $400{ }^{\circ} \mathrm{C}$ substrate temperature. It decreases then when the substrate temperature is increases. This fact is may attributed to the transformation of some of nano-crystalline iridium oxide molecules to the $\operatorname{Ir}(\mathrm{OH})_{3}$ sites which produces higher ion mobility during the colouring and the bleaching processes. The reduction in the films optical modulation at higher substrate temperature is may be affected by the increase in the crystallite size as well as by the formation of compact films [21], [22].

\section{Colouration Efficiency}

The colouration efficiency is an important parameter while characterizing the electrochromic devices. It is estimated to be the ratio of the change in the optical density to the amount of charge injected into the film unit area. According to the Beer-Lambert's law, the change in the optical density $(\Delta \mathrm{OD})$ of the film is defined as the natural logarithm of the transmittance variation between the bleached and the coloured states measured at fixed wavelength $(630 \mathrm{~nm})$ [23]. Therefore,

$$
\Delta O D=\ln \left(\frac{T_{c}}{T_{b}}\right)
$$

where $T_{b}$ and $T_{c}$ are the transmittance of the bleached and the colored states, respectively.

The bleached state is defined to be the value found at the end of the cyclic voltammogram (at $\pm 0.8 \mathrm{~V}$ applied voltage), where the current density is recovered back to its original value. The coloured state is similarly defined at the end of the colouring.

The optical density as related to the substrate temperature and the solution molarity are shown in Tables I and II respectively. The colouration efficiency (CE) was calculated at $630 \mathrm{~nm}$ optical wavelength using the relation;

$$
C E=\triangle O D / Q_{i}
$$

where $Q_{i}$ is the amount of charge intercalated in the sample estimated through integrating the area under the curve of current density versus the colouring or the bleaching period of time. An increase in the values of the change in the optical density $(\triangle \mathrm{OD})$ and the colouration efficiency $(\mathrm{CE})$ occurs as the doping concentration increases. The optimum preparation conditions that obtained from Fig. 6, produce the maximum change in the optical density and the maximum colouration efficiency are found to be $400{ }^{\circ} \mathrm{C}$ substrate temperature, 0.02 $\mathrm{M}$ solution molarity and $10 \mathrm{~min}$ deposition period of time. These observations are in good agreement with other published results for sprayed iridium oxide films [2], [20].
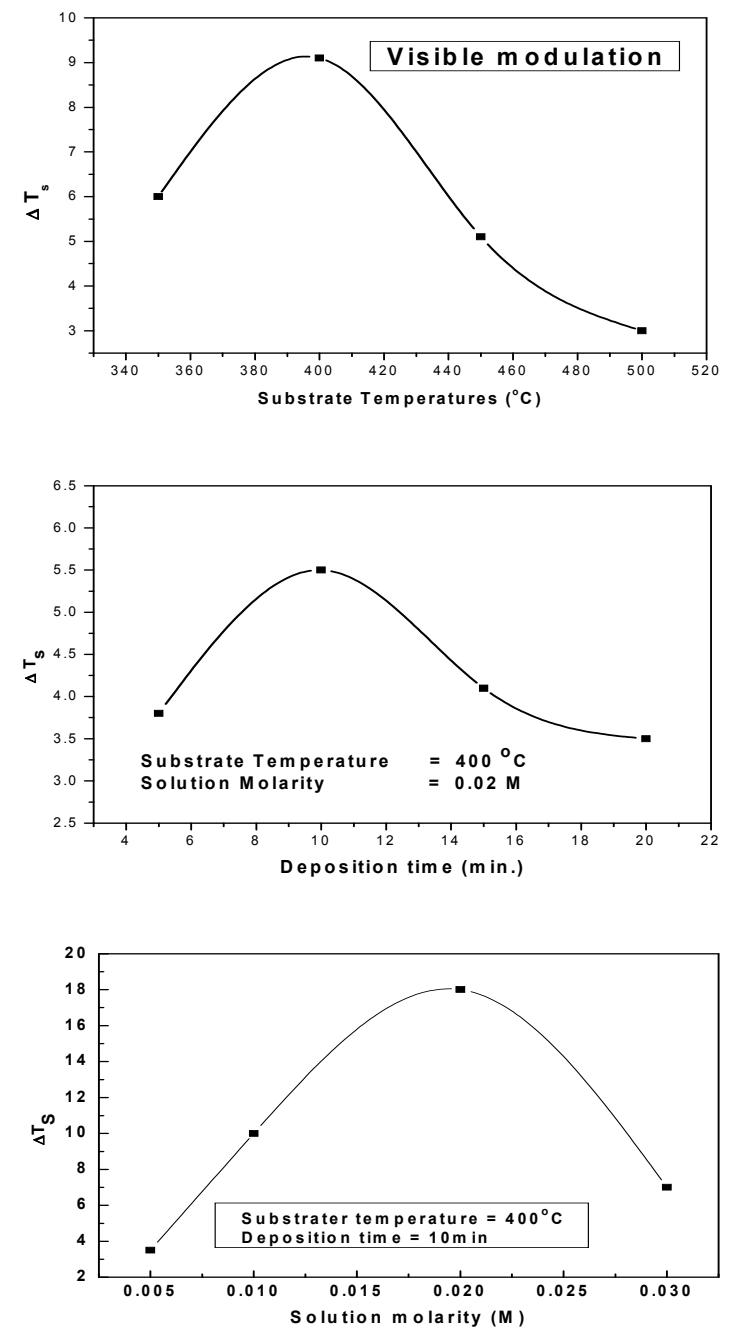

Fig. 6. Visible modulation as a function of substrate temperature, deposition time and solution molarity.

\section{CONCLUSION}

- Amorphus and nanocrystalline iridium oxide thin films were deposited onto ITO coated glass substrates using iridium chloride as an aqueous solution using spray pyrolysis technique under the effect of deposition conditions.

- XRD patterns showed that the crystalline size for the polycrystalline thin films are of around $14 \mathrm{~nm}$ for the scanning range of preparative conditions.

- Electrochromic behaviour was investigated in $\mathrm{H}_{2} \mathrm{SO}_{4}$ 
electrolyte as related to the various preparative conditions namely, the substrate temperature, the solution molarity and the deposition time.

- The iridium oxide films deposited at $400{ }^{\circ} \mathrm{C}$ substrate temperature, $0.02 \mathrm{M}$ solution molarity and $10 \mathrm{~min}$ deposition period of time were found to exhibit the highest pronounced electrochromic activity compared to those films deposited at other values of the same parameters.

- Change in colouration to bleaching states, upon polarization, for the spray-deposited Ir-oxide thin films is mainly attributed to the well-known $\mathrm{Ir}^{3+} \leftrightarrow \mathrm{Ir}^{4+}$ intervalance charge transfer reactions.

\section{REFERENCES}

[1] G. Granqvist, Handbook of Inorganic Electrochromic Materials, Amsterdam, Netherland: Elsevier Science, 1995.

[2] P. S. Patil, R. K. Kawar, and S. B. Sadale, Electrochim. Acta, vol. 50, pp. $2527,2005$.

[3] C. M. Lampert, Sol. Energy Mater, vol. 19, pp. 1, 1989.

[4] P. M. S. Monk, R. J. Mortimer, and D. R. Rosseinsky, Electrochromism: Fundamentals and Applications, VCH, Weinheim, 1995.

[5] S. H. Lee and S. K. Joo, Solar Energy Materials and Solar Cells, vol. 39, pp. $155,1995$.

[6] A. A. Gewirth and M. S. Thorum, Inorg. Chem., vol. 49, pp. 3557, 2010.

[7] V. M. Tolosa, K. M. Wassum, N. T. Maidment, and H. G. Monbouquette, Biosensors and Bioelectronics, vol. 42, pp. 256, 2013.

[8] M. Li, Y. B. Wang, X. Zhang, Q. H. Li, Q. Liu, Y. Cheng, Y. F. Zheng, T. F. Xi, and S. C. Wei, Materials Science and Engineering C, vol. 33, pp. $15,2013$.

[9] C. H. Chang, T. S. Yuen, Y. Nagao, and H. Yugamia, Journal of Power Sources, vol. 195, pp. 5938, 2010.

[10] G. Beni and J. L. Shay, Appl. Phys. Lett, vol. 33, pp. 567, 1978.

[11] S. Gottesfeld, J. D. E. Mcintyre, G. Beni, and J. L. Shay, Phys. Lett, vol. 33 pp. 208, 1978.

[12] Y. Sato, Vacuum, vol. 41, pp. 1178, 1990

[1]. K. Yamanaka, Jpn. J. Appl. Phys., vol. 30, pp. 1285, 1991.

[13] S. Hackwood, A. H. Dayen, and G. Beni, Phys. Rev. (B), vol. 26, pp. $471,1982$.

[14] S. L. Vot, L. Roue, and D. Belanger, Electrochim. Acta., vol. 59, pp. 49, 2012.

[15] Y. Takasu, S. Onone, K. Kameyama, Y. Murakami, and Y. Kozawa, Electrochim. Acta, vol. 39, pp. 1993, 1994.

[16] S. A. Mahmoud, A. A. Akl, and S. M. Al-Shomar, Physica B, vol. 404 pp. 2151, 2009.

[17] S. A. Mahmoud, Solid State Science, vol. 4, pp. 221, 2002.

[18] R. K. Kawar, P. S. Chigare, and P. S. Patil, Appl. Surface Sci., vol. 206 pp. 90, 2003.

[19] P. S. Patil, R. K. Kawar, and S. B. Sadale, Applied Surface Science, vol. 249, pp. 367, 2005.

[20] P. S. Patil, S. H. Mujawar, A. I. Inamdar, and S. B. Sada, Applied Surface Science, vol. 250, pp. 117, 2005.

[21] T. S. Yang, Z. R. Lin, and M. S. Wong, Applied Surface Science, vol. 252, pp. 2029, 2005.

[22] P. W. Atkins, Physical Chemistry, Oxford University Press, 1994.

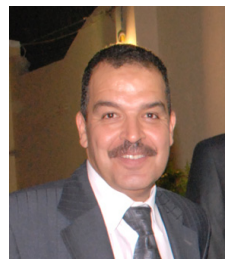

Safwat Abdel-Halem Mahmoud was born on 23th April 1962 in Egypt. He obtained his master in El-minia University, Egypt and PHD degree (with concentration on thin films technology and surface science), from Faculty of Science, Physics Department, Leipzig University, Germany. He had his first degree in Faculty of Sciences, University of Minia at Egypt. He had been an active researcher and lecturer at many universities and Institutions, in Egypt and Germany. He is currently working as Professor in Hail University in KSA, His current research interests in Experimental Solid State Physics, General: Solid state physics, thin film technology, material science, nanotechnology and smart materials. Specific: Synthesis of nanocrystalline particles via wet chemical method. producing transparent conductive coatings on different glass and polymeric substrates through Spray Pyrolyses techniques. Thin film Characterization (electrical, optical, mechanical, structural and surface properties).He has a track record of fundamental research on these topics which is documented by numerous publications. He has been reviewer for numerous journals and indexed papers, such as IEEE and Science Direct.

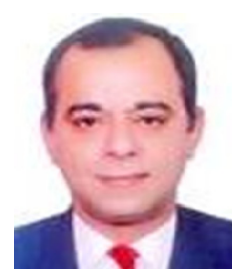

Adel Saber Riad was born on 25th Mai 1954 in Egypt. He obtained his master in El-Minia University, Egypt and $\mathrm{PhD}$ degree (with concentration on semiconductors solar cells), from Faculty of Science, Physics Department, York University, England. He had his first degree in Faculty of Sciences, University of Minia at Egypt. He had been an active researcher and lecturer at many universities and Institutions, in Egypt. He is currently working as Professor in Hail University in KSA, His current research interests are Experimental Solid State Physics General: Solid state physics, thin film technology, material science, nanotechnology and smart materials. Specific: Semiconductors. He has a track record of fundamental research on these topics which is documented by numerous publications. He has been reviewer for numerous journals and indexed papers, such as IEEE and Science Direct.

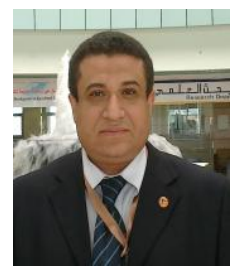

Mohamed El-Deeb was born on October 27, 1974. He has a B.Sc (Hons) in chemistry (1995), M.Sc in physical chemistry (1999), Ph.D in physical chemistry (2005) from Cairo University (Beni-Suef Branch). He is an associated professor of physical chemistry at Chemistry Department, Faculty of Science, Beni-Suef University, Egypt. He has a large experience in electrochemistry of conducting polymers as well as the deposition and characterization of metals and alloys. He has published more than 20 research papers in various International Journals.

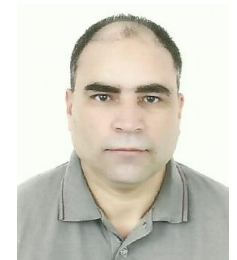

Tarek Ben Nasrallah was born on 8th August, 1961 in Tunisia. He obtained his first degree, master, and $\mathrm{PhD}$ degree (with concentration on electronic devices), from Faculty of Science and Technology, Physics Department, Nantes University, France. He had been an active researcher and lecturer at many Institutions in Tunisia and France. He is currently working as a professor in Hail University in KSA. His current research interests are thin film technology, optoelectronics devices. 